http://dx.doi.org/10.30681/23588403v13i0201

\title{
UNEMAT: RENOMEAÇÃO E NOVOS SENTIDOS EM UMA PERSPECTIVA ENUNCIATIVA ${ }^{1}$
}

\author{
Data de recebimento: 02/09/2020
}

Aceite: 05/10/2020

\author{
Lygia Cristina Menezes de LIMA (PPGL/UNEMAT) ${ }^{2}$ \\ Eduardo GUIMARÃES (PPGL/UNEMAT) ${ }^{3}$
}

\begin{abstract}
Resumo: Neste artigo analisamos à luz da Semântica do Acontecimento, teoria desenvolvida por Guimarães $(2002,2004,2017,2018)$, o processo de renomeação da Universidade do Estado de Mato Grosso (Unemat) por Universidade Estadual de Mato Grosso Carlos Alberto Reyes Maldonado. Este estudo analisa de forma semântico-enunciativa o acontecimento que ao instituir a sua própria temporalidade, coloca em disputa o político no processo de renomeação de uma instituição de ensino superior instalada a partir de uma cidade do interior de Mato Grosso em uma Universidade do Estado. No processo da última renomeação da universidade, ao renomear a instituição com o objetivo de prestar uma homenagem a um de seus idealizadores, instala-se um litigio entre formas de nomear e designar (a da proposta da Unemat, de um lado, e a que foi aprovada pela assembleia legislativa de Mato Grosso), afetando o próprio sentido da homenagem pretendida pela Universidade
\end{abstract}

Palavras-chave: Unemat, Nomeação, Renomeação, litigio, Semântica do Acontecimento.

\begin{abstract}
In this research, we analyze, under the light of the Semantics of the Event, a theory developed by Guimarães $(2002,2004,2017,2018)$, the process of renaming the Mato Grosso State University (Unemat) into Carlos Alberto Reyes Maldonado Mato Grosso State University. This study analyze, in a semantic-enunciative form, the event that, to institute its own temporality, put into dispute the politics in the renaming process of a higher learning institution installed from a Mato Grosso inland city into a State University. During the last renaming process of the University, in renaming the institution with the objective of pay homage to one of its ideaters, a litigation is established between the forms of naming and designating (the proposal by Unemat, on one side, and the one aproved by the Legislative Assembly of Mato Grosso), affecting the own meaning of the homage intended by the University.
\end{abstract}

Key-words: Unemat, Naming, Renaming, Litigation, Semantics of the Event

\footnotetext{
${ }^{1}$ Este artigo apresenta fragmentos do acontecimento enunciativo “ (RE)NOMEAÇÕES E SENTIDOS - UMA ABORDAGEM SEMÂNTICO-ENUNCIATIVA DO NOME UNEMAT” Dissertação de Mestrado apresentada ao Programa de Pós-Graduação Stricto Sensu em Linguística, da Universidade do Estado de Mato Grosso UNEMAT, como requisito parcial para obtenção do título de Mestra em Linguística, com a Orientação do professor Dr. Eduardo Roberto Junqueira Guimarães. Linha de Pesquisa: Estudo de Processos de Significação. Dissertação defendida e aprovada em 07/05/2020.

${ }^{2}$ Mestranda em Linguística pela Universidade do Estado de Mato Grosso/Unemat. E-mail: lygiajornalismo@unemat.br

${ }^{3}$ Professor doutor do Programa de Pós-Graduação em Linguística da Universidade do Estado de Mato Grosso / Unemat. E-mail: eduardo.gui@uol.com.br
} 


\section{Introdução}

A Unemat, Universidade do Estado de Mato Grosso, ou Universidade Estadual de Mato Grosso Carlos Alberto Reyes Maldonado, mais recentemente, é a única universidade pública mantida pelo Executivo Estadual de Mato Grosso. A princípio, pensar Universidade do Estado de Mato Grosso ou Universidade Estadual de Mato Grosso como sinônimos, seria natural, mas neste trabalho veremos que estes nomes não são exatamente sinônimos.

Antes da existência da Unemat, uma outra universidade ocupou esse posto por uma década, a UEMT (Universidade Estadual de Mato Grosso), criada em 1969, e em 1979 deixa de existir e é transformada ${ }^{4}$. Essa universidade, com a divisão do Estado de Mato Grosso em 1979, acabou sendo federalizada, deixando uma lacuna no ensino superior em Mato Grosso. Lacuna essa que foi preenchida no momento em que o poder Executivo estadual decide novamente financiar a educação superior por meio do Instituto de Ensino Superior de Cáceres (IESC), instituição criada pelo município e que, em 1985, passa por um processo de modificação, o que inclui sua renomeação.

A partir desta mudança, em que o Estado de Mato Grosso assume financeiramente a Instituição de Ensino Superior criada em Cáceres, a mesma passa por diversos processos de (re)nomeação e transformações até que em 1993 é transformada em Universidade com o nome de Universidade do Estado de Mato Grosso. Desta forma, depois de 23 anos, o estado de Mato Grosso volta a ter uma Universidade mantida pelo poder estadual.

Nosso objetivo neste artigo é analisar, na perspectiva da Semântica do Acontecimento, teoria desenvolvida por Guimarães, como essa renomeação mais recente, ocorrida em janeiro de 2019, muda o sentido e desconsidera a história de luta desta universidade e de um de seus idealizadores, justamente na tentativa de homenageá-lo. Essa mudança no nome da Unemat instala ainda um litigio, uma vez que a Reitoria da instituição requer e mantém o uso de Universidade do Estado de Mato Grosso, resistindo à atual renomeação.

Guimarães afirma em Semântica, Enunciação e Sentido (2018, p.173) que "entre os nomes próprios há alguns que têm grande importância na prática da linguagem: nomes próprios de pessoa, nomes de lugares (países, cidades, ruas, praças, etc), instituições”. Mas para ele, o fundamental é que o "nome próprio é um nome que num acontecimento de enunciação refere a um objeto único". Mas não pode ser considerado apenas como mera

\footnotetext{
${ }^{4}$ Sobre a trajetória da Universidade Estadual de Mato Grosso ver Benfica (2016 e 2019)
} 
identificação ou "rótulo", o nome próprio tem uma história marcada por acontecimentos sócio-históricos que determinam este nome num acontecimento de linguagem. E é porque significam que referem a algo (Guimarães, 2018).

Dito isto, sabemos que no caso das nomeações, ainda que divergentes da Unemat, elas se referem a um objeto único por meio do funcionamento do nome próprio, pelo que designam (significam) no acontecimento. Neste caso, enunciar o nome Universidade do Estado de Mato Grosso ao longo de sua história de existência, vai fazendo sentido e significando por meio das enunciações e dos memoráveis que vão sendo evocados.

Segundo Guimarães (Idem) nomear é dar existência histórica a algo, a alguém, nessa perspectiva, pensando a análise sobre a constituição do nome próprio da Universidade, podemos dizer que a enunciação que nomeia, constitui uma temporalidade própria (presente, passado e futuro) que atribui sentidos e passa a dar existência histórica ao nome. Pensar o nome somente como forma de classificar algo é não dar importância aos aspectos históricosociais que determinam o nome e que contribuem para a história do próprio nome.

Sobre a renomeação, Guimarães (2018, p.206) afirma que "Estes modos de nomear e renomear mostram um aspecto importante, a necessidade social de produzir uma relação de unicidade como própria deste funcionamento". Para ele tanto nos casos de nomes próprios de pessoas, como de nomes próprios em geral, o que é o caso da Universidade do Estado de Mato Grosso (Unemat), o funcionamento é assemelhado:

Assim esta prática de atribuir nomes a coisas específicas, como a produzir uma unicidade do nome, é claramente um processo exposto necessariamente ao litígio político dos acontecimentos de enunciação. E é em meio a este litígio que a referência funciona, mesmo que a designação, própria de um nome e de outro nome que renomeia o que o primeiro nomeava, seja modificada, e é sempre pelos processos de renomeação . E a cada vez, a referência se fará, em virtude da designação (com que ela significa) que a nomeação ou a renomeação tiverem constituído numa história enunciativa específica. (GUIMARÃES, 2018, p. 215).

No nosso entendimento o processo de nomeação, renomeação e designação que significa no nome Universidade do Estado de Mato Grosso dá sentido à trajetória da instituição e o litígio do nome faz parte da sua história.

\section{Contextualização Histórica:}


A Trajetória da Unemat tem início com o Instituto de Ensino Superior de Cáceres (IESC) que foi criado oficialmente no dia 20 de julho de 1978. De acordo com a página oficial da Unemat na internet, o IESC traz como marca o fato de ter nascido no interior com a meta de promover o ensino superior e a pesquisa. A criação de um Instituto de Ensino Superior em Cáceres parte de uma reinvindicação social, de cobrança pelo cumprimento de promessas eleitorais ${ }^{5}$, que veio se consolidar durante as comemorações do bicentenário do município.

Todo o percurso histórico, no processo de constituição do ensino superior público em Cáceres, não menciona a existência de outros cursos e institutos de nível superior (UEMT) no interior de Mato Grosso, ainda uno, pois a implementação da divisão do Estado só ocorreria em $1^{\circ}$ de janeiro do ano seguinte, enquanto o decreto municipal que criou o IESC é datado de 20 de julho de 1978.

O IESC funcionou entre os anos de 1978 a 1985. Foram anos marcados por dificuldades financeiras e estruturais que mobilizaram a sociedade cacerense a buscar a federalização do Instituto ${ }^{6}$ a fim de resolver inclusive a questão dos acadêmicos formados pela instituição, que não tinham seus diplomas reconhecidos. É com esse dilema de formados sem diploma, que começa a circular no IESC o desejo de ter uma universidade estadual. Desponta nesse cenário a reivindicação da criação da Universidade Estadual do Vale do Guaporé, expressa em uma matéria publicada no Jornal Diário de Cuiabá, do dia 27 de outubro de $1985^{7}$ sob o título "Universidade Estadual do Vale do Guaporé, a grande aspiração".

Como a federalização não se consolidou, o governo estadual, $\operatorname{pressionado}^{8}$ acabou encaminhando à Assembleia Legislativa o projeto de Lei estadualizando o IESC e transformando-o em Fundação Centro Universitário de Cáceres (FCUC). No entanto, uma recomendação do Conselho Federal de Educação alterou a nomeação da Fundação Centro Universitário de Cáceres para Fundação Centro de Ensino Superior de Cáceres. Essa mudança ocorre a partir da aprovação da Lei Estadual no 5.495, de 17 de julho de 1989.

Foi durante a existência da Fundação Centro de Ensino Superior de Cáceres que o professor Carlos Alberto Reyes Maldonado foi eleito pela comunidade acadêmica como coordenador da Instituição. O nome do professor Carlos Alberto Reyes Maldonado ficará

\footnotetext{
${ }^{5}$ ZATTAR, 2008, p. 18

${ }^{6}$ Zattar, Neuza, et all. 2018, p.142.

${ }^{7}$ Zattar, 2008, p. 49 e p.61 e 62.

${ }^{8}$ Zattar, Neuza, et all. 2018, p.144.
} 
marcado em toda a trajetória institucional e culminará como o estopim para o último processo de renomeação vivenciado na Universidade em 2019, o que veremos mais à frente.

Em 1992, a Lei Complementar $n^{\circ}$ 14, de 16 de janeiro, determina que a Fundação Centro de Ensino Superior de Cáceres (FCESC) passe a denominar-se Fundação de Ensino Superior de Mato Grosso (FESMT). O ano de 1993 é decisivo na trajetória de nomeações, (re)nomeações e transformações da Unemat, pois em 15 de dezembro de 1993, através da Lei Complementar $\mathrm{n}^{\mathrm{o}}$ 30, institui-se a Universidade do Estado de Mato Grosso (Unemat), mantida pela Fundação Universidade do Estado de Mato Grosso (FUNEMT), que transformou em campi os antigos núcleos pedagógicos.

Já como Universidade, foi instalada em 2 de fevereiro de 1994, o ato realizado em Cáceres contou com a presença de diversas autoridades civis e acadêmicas. Foi em 1994 que são implantados os primeiros cursos de bacharelado, além de ser criado o campus de Colíder e Barra do Bugres. No ano seguinte (1995), a Unemat incorpora o Centro de Ensino Superior de Tangará da Serra (Cesut) e o transforma em campus. Os estatutos da Fundação Universidade do Estado de Mato Grosso são aprovados em 10 de janeiro de 1995 pelo Conselho Estadual de Educação (CEE). O credenciamento da Unemat pelo CEE ocorre em 10 de agosto de 1999, data em que a instituição passa a registrar os seus diplomas, o que anteriormente era feito pela UFMT. Este percurso é um percurso institucional que tem como correlato uma história de renomeações que produzem a reidentificação daquilo que se nomeia (uma instituição universitária específica).

Atualmente a Unemat conta com 13 (treze) campi, 17 (dezessete) núcleos pedagógicos e 24 (vinte e quatro) polos educacionais de Ensino a Distância. Cerca de 22 mil (vinte e dois mil) acadêmicos são atendidos em 60 (sessenta) cursos presenciais e em outros 129 (cento e vinte e nove) cursos ofertados em modalidades diferenciadas. Na Pós-graduação, conta com 24 (vinte e quatro) Programas de Pós-graduação Stricto Sensu aprovados pela Capes. Estes programas contemplam 28 (vinte e oito) cursos de Pós-graduação Stricto Sensu, sendo no total 21 (vinte e um) Mestrados (11 (onze) mestrados acadêmicos, 01 (um) mestrado profissional e 09 (nove) mestrados profissionais em rede), bem como 07 (sete) doutorados, sendo 04 (quatro) doutorados acadêmicos institucionais e 03 (três) doutorados acadêmicos em rede. $^{9}$

9 Dados atualizados em abril 2019. Disponível em: http://portal.unemat.br/?pg=site\&i=prppg\&m=posgraduacao \&c=\&secao=2427. Acesso em: 25 de setembro 2019 . 
Com o falecimento do professor Carlos Maldonado em 30 de janeiro de 2016, os conselhos da Unemat aprovaram a alteração do nome da instituição a fim de homenageá-lo. Maldonado foi o primeiro coordenador eleito da então Fundação Centro de Ensino Superior de Cáceres (FCESC), depois foi o diretor presidente da Fundação de Ensino Superior de Mato Grosso e um dos principais articuladores para a criação da Universidade do Estado de Mato Grosso, assumindo o cargo de primeiro reitor da instituição, inicialmente indicado e posteriormente eleito pela comunidade acadêmica.

\section{Universidade Estadual de Mato Grosso "Carlos Alberto Reyes Maldonado"}

Depois de 15 anos de criação da Universidade do Estado de Mato Grosso, a instituição passa por um novo processo de renomeação, desta vez para homenagear o primeiro reitor, e também um dos idealizadores da Unemat, e neste caso sem nenhuma mudança institucional envolvida. É importante ressaltar aqui que esse acontecimento de renomeação não parte do lugar institucional, do governo de Mato Grosso como nas renomeações anteriores, mas parte da comunidade acadêmica, que inclusive, encontra resistência por parte do governador, como veremos logo a seguir.

A partir da decisão dos conselhos de renomear a Universidade para homenagear o professor Carlos Maldonado, foi encaminhada uma proposta à Assembléia Legislativa de Mato Grosso solicitando a inclusão de seu nome no nome da Unemat. A aprovação da Lei Complementar $\mathrm{n}^{\circ} 611$ que renomeia a universidade por Universidade Estadual de Mato Grosso “Carlos Alberto Reyes Maldonado” se deu em 28 de janeiro de 2019.

[R1]

\section{LEI COMPLEMENTAR Nº 611, DE 28 DE JANEIRO DE 2019.}

Autor: Deputado Professor Adriano Modifica a denominação da Universidade Estadual de Mato Grosso. O PRESIDENTE DA ASSEMBLEIA LEGISLATIVA DO ESTADO DE MATO GROSSO, no desempenho da atribuição conferida pelo art. $42, \S 8^{\circ}$, da Constituição Estadual, promulga a seguinte Lei:

Art. $1^{\circ}$ A Universidade Estadual de Mato Grosso, criada pela Lei Complementar $\mathrm{n}^{\mathrm{o}} 30$, de 15 de dezembro de 1993, passa a denominar- 
se Universidade Estadual de Mato Grosso "Carlos Alberto Reyes Maldonado" - UNEMAT.

Art. $2^{\circ}$ Esta Lei Complementar entra em vigor na data de sua publicação. Assembleia Legislativa do Estado, em Cuiabá, 28 de janeiro de 2019. Original assinado: Dep. Eduardo Botelho Presidente

Iniciemos nossa discussão sobre este acontecimento de renomeação, considerando que “o processo de nomeação e renomeação funciona segundo o caráter político da enunciação" (GUIMARÃES, 2018, p. 211). Assim, o alocutor-presidente da Assembleia Legislativa, pela performatividade que altera o nome, assume o lugar de dizer de um enunciador universal que significa a mudança como para todos e para sempre (enquanto dure). O que se enuncia em "Art. $1^{\circ}$ A Universidade Estadual de Mato Grosso, criada pela Lei Complementar $\mathrm{n}^{\circ} 30$, de 15 de dezembro de 1993, passa a denominar-se Universidade Estadual de Mato Grosso “Carlos Alberto Reyes Maldonado" - UNEMAT”.

$\mathrm{O}$ ato enunciativo apresenta a disputa do real, do político, no modo de significar o real. Para isso vale uma contextualização sobre o processo de renomeação até chegar à promulgação desta lei. A proposta de alteração da nomeação da Unemat, foi aprovada logo após a morte do professor Carlos Maldonado, em 2016. O percurso para que o desejo da comunidade acadêmica em alterar a denominação da Instituição se concretize é marcado por diversos acontecimentos enunciativos. Primeiro, o Conselho Universitário aprova a proposta de renomear por Universidade do Estado do Mato Grosso "Carlos Alberto Reyes Maldonado" - UNEMAT; segundo, a apresentação do projeto de lei na Assembleia até sua aprovação em março de 2018; terceiro, o veto do governador, em abril de 2018, alegando que o projeto continha vício de iniciativa; quarto, a derrubada do veto pelos deputados e a promulgação da lei prevendo a alteração no nome em janeiro de 2019.

Desta forma, a enunciação que nomeia a Unemat, que segundo a lei passa a denominar-se Universidade Estadual de Mato Grosso Carlos Alberto Reyes Maldonado, contém em si, outras enunciações, uma trajetória de enunciações anteriores.

Este texto da Lei Complementar nos apresenta uma nomeação e uma renomeação que significa e se refere a vários lugares. Dentre eles podemos citar a classe de professores, reitores, funcionários e alunos que ao lutar por um ato de homenagem se colocam também no lugar do homenageado. Mas essa renomeação que busca prestar uma homenagem, é a única 
entre os processos renomeativos da Unemat, que não parte do alocutor-governador e nem é aceita por ele.Neste aspecto o projeto de lei apresentado à Assembleia Legislativa (anexo 1) já apresenta a proposta de renomeação como Universidade Estadual de Mato Grosso tal como aprovado pelos deputados, mesmo que na justificativa da proposta apareça o nome da instituição como Universidade do Estado de Mato Grosso e também como Universidade Estadual de Mato Grosso.

Sobre a forma de nomear e designar a instituição como Universidade Estadual de Mato Grosso, ou Universidade do Estado de Mato Grosso é importante pensar os sentidos ai envovidos. Ou seja, os nomes designam (significam) do mesmo modo? Identificam a instituição do mesmo modo? Observe-se o seguinte: o nome da universidade é modificado assumindo o modelo de nomear estas instituições mais utilizado no Brasil (Universidade Estadual de X, onde X é um nome de Estado da Federação) e que rondava a nomeação da universidade desde o início, em substituição ao nome dado à universidade no modo Universidade do Estado de X. Neste processo manteve-se, sempre a estabilidade da sigla Unemat.

Dada esta renomeção, cujos desdobramentos ainda não podemos conhecer, observemos o sentido que a própria articulação sintático semântica dos nomes proporcionam. Consideremos inicialmente Universidade do Estado de Mato Grosso.

A primeira coisa a considerar é que este nome renomeia Fundação de Ensino Superior de Mato Grosso que renomeara a Fundação Centro de Ensino Superior de Cáceres - FCESC. Ou seja, há um sintagma, de Cáceres, que é substituído por outro, de Mato Grosso, numa relação entre o nome de uma cidade e o nome do Estado. Isto articula o nome Universidade do Estado de Mato Grosso mais diretamente na história da Universidade. Por outro lado, Universidade Estadual de Mato Grosso, se correlaciona com um padrão de nomeação de universidades muito comum no Brasil. Assim, o nome Universidade do Estado do Mato Grosso significa a história mais específica dos acontecimentos que começa no IESC e chega à Universidade do Estado do Mato Grosso (Unemat), enquanto o outro nome, Universidade Estadual de Mato Grosso, significa num padrão de nomeação exógeno ao processo histórico em questão. Ambas as expressões referem-se ao mesmo ente institucional, mas o sentido que continua em litígio é o sentido da origem da Universidade (Unemat), que ela reivindica, ao se considerar com 42 anos, e o sentido de ser como outras universidades estaduais, esmaecendo o sentido da luta histórica de sua formação. 
Um aspecto particularmente importante está na Lei Complementar que cria a Unemat. Nela apresentamos, de um lado, que a Lei Complementar "cria a Universidade do Estado de Mato Grosso, extingue a Fundação Ensino Superior de Mato Grosso; e...”, Ou seja, a nomeação da fundação não traz o determinante estadual. Este acontecimento tem como memorável acontecimentos de nomeação anteriores nesta história institucional e de renomeações: a) Fundação Centro Universitário de Cáceres, estabelecido e nomeado por lei estadual; b)Fundação Centro de Ensino Superior de Cáceres, que renomeia a fundação indicada em $a$; c) Fundação de Ensino Superior de Mato Grosso, que renomeia a fundação indicada em $b$, que renomeara a fundação indicada em $a$. Ou seja, o nome Universidade do Estado de Mato Grosso significa nesta história de acontecimentos de enunciação. E é essa história de sentidos que é desviada para um outro modo de nomear cujo memorável são as enunciações de nomes de universidades estaduais do Brasil em geral, no modelo universidade estadual de $X$.

Um aspecto, não central, mas que pode ser colocado, na medida da história de sentidos que colocamos acima, é a consideração do sentido específico que do Estado de Mato Grosso assumiu na diferença com a história de enunciações em que se apresenta o determinante estadual em nomes como universidade estadual de $X$ (onde $\mathrm{X}$ é nome de um estado brasileiro).

É evidente que Universidade do Estado de Mato Grosso poderia ser sinônimo de Universidade Estadual de Mato Grosso. Mas, esta sinonímia não se realiza plenamente pela própria história de renomeações que apresentamos. E nesta medida, poderíamos dizer que, não se considera, nestas condições, como sinônimos, os enunciados:

(a)A Universidade do Estado de Mato Grosso é uma universidade de todo o Estado de Mato Grosso.

(b)A Universidade Estadual de Mato Grosso é a universidade de todo o Estado de Mato Grosso.

$\mathrm{Na}$ história aqui considerada, o enunciado (b) não faz muito sentido. O que dá ao nome Universidade do Estado de Mato Grosso um sentido que é predicado por Unemat é de todo o Estado do Mato Grosso. Este aspecto da significação do nome Universidade do Estado 
de Mato Grosso, está assim colocado em questão, como mais um elemento afetado pela mudança recente do nome.

Podemos perceber um processo de designação em que do Estado de Mato Grosso indica todo um caminho histórico. De outro modo significa o nome Universidade Estadual de Mato Grosso. A partir desta enunciação da nova lei que renomeou por Universidade Estadual, temos o memorável (enunciações da mídia e de pessoas em geral) de uma universidade estadual, como outras, aí inscrito. Em toda a enunciação não aparece o nome pelo qual a Unemat foi nomeada e designada, no seu momento de criação enquanto parte de uma história iniciada muito antes, própria da cidade de Cáceres, ou seja, Universidade do Estado de Mato Grosso.

A iniciativa desta lei é fazer uma homenagem, agregando ao nome da instituição o nome do professor Carlos Alberto Reyes Maldonado, de modo que temos uma relação predicativa de aposição, nessa renomeação, na prática faz ressignificar dois nomes, a Instituição e o nome de seu criador, uma vez que o nome Carlos Alberto Reyes Maldonado funciona como aposto da Universidade.

Nos parece, tal como afirma Guimarães (2017: 49 e 50) que a forma como foi designada e nomeada inicialmente a Unemat, como Universidade do Estado de Mato Grosso, quis particularizá-la, afirmando ser essa a universidade do Estado, como a única que é mantida e criada pelo Estado, significando também a relação de passagem da cidade para o Estado. Assim, se no momento de prestar uma homenagem a um dos seus idealizadores, modifica-se essa nomeação primeira, a homenagem fica também modificada, pois desvincula o nome de Carlos Alberto Reyes Maldonado do nome da universidade ligado ao seu trabalho de fundação. Afinal "o sentido do nome próprio lhes constitui, em certa medida" (2017: 54), exatamente pela história que neles significa.

Outro ponto que chama a atenção é que a despeito da denominação ser Universidade Estadual de Mato Grosso “Carlos Alberto Reyes Maldonado”, a própria Unemat em seu portal oficial de notícias, e também em diversos documentos oficiais continua a designá-la como "Universidade do Estado de Mato Grosso. Mesmo, na enunciação que anuncia a homologação da homenagem publicada no portal www.unemat.br em 16 de janeiro de 2019 temos:

[R 2]

\section{Definitivo}


Unemat passa a ser Universidade do Estado de Mato Grosso

\section{Carlos Alberto Reyes Maldonado}

Chega ao fim o impasse do nome da Universidade do Estado de Mato Grosso (Unemat) que se estendia desde 2016. Os deputados da Assembleia Legislativa de Mato Grosso (ALMT) derrubaram nesta terça-feira (15), por 15 a 2, o veto do ex-governador Pedro Taques, publicado no dia 20 de abril de 2018, que rejeitava a alteração do nome da Instituição para Universidade do Estado de Mato Grosso

\section{Carlos Alberto Reyes Maldonado.}

“A derrubada do veto é um reconhecimento da autonomia da Universidade em definir suas políticas e o reconhecimento do trabalho do professor Maldonado junto a Instituição e o Estado. Dar seu nome à Universidade que ele trabalhou para expandir e que hoje atende todo o estado de Mato Grosso é digno de sua atuação", comentou o reitor da Unemat, Rodrigo Zanin.

O Projeto de Lei Complementar $N^{o}$ 03/2016 foi aprovado por unanimidade na ALMT em 21 de março de 2016. À época, o então governador justificou o veto por entender se tratar de vício formal, apresentado em flagrante ultraje ao princípio da separação dos Poderes, justificativa agora apreciada e não acatada pelo Legislativo.

A proposta de alteração do nome havia sido feita junto à ALMT em fevereiro de 2016 pelo então deputado estadual Adriano Silva, professor e ex-reitor da Unemat, para atender um anseio da comunidade acadêmica da Instituição. O desejo de homenagear Maldonado, que morreu às vésperas de completar 55 anos de idade, em 30 de janeiro de 2016, ficou registrado ao ser aprovada alteração do nome por representantes de todos os câmpus da Universidade durante o Conselho Universitário (Consuni) da Unemat, realizado em março do mesmo ano.

A partir deste acontecimento de enunciação temos logo no topo da matéria, o que no jornalismo se chama "chapéu", o enunciado "Definitivo". Esse enunciado por si só, faz aparecer o sentido de que em uma enunciação anterior, não era definitivo, ou que era 
provisória. A partir do enunciado título "Unemat passa a ser Universidade do Estado de Mato Grosso Carlos Alberto Reys Maldonado" vemos que a enunciação anterior de Universidade do Estado, se faz presente, apesar da lei aprovada afirmar que a denominação passa a ser Universidade Estadual. Esta forma de enunciação é retomada em todo o texto deixando evidente esse litígio. Em outros termos, a própria Unemat, nas suas enunciações resiste sustentando o nome que conta sua história.

Vale lembrar que há uma história de renomeações em que o nome oficial da instituição é o que aparece no nome da instituição. No momento em que o nome passa a ser Universidade do Estado de Mato Grosso, a mídia renomeia e designa a universidade por Universidade Estadual de Mato Grosso, e no fim do percurso de renomeações a renomeação por Universidade Estadual de Mato Grosso Carlos Maldonado, o Estado do Mato Grosso assume a nomeação que a mídia dava à universidade, no entanto a universidade mantém o litígio, se afirmando como Universidade do Estado de Mato Grosso e, ao negar a nomeação Universidade Estadual de Mato Grosso, procura manter o vínculo entre o nome Universidade do Estado de Mato Grosso, e o nome de um de seus fundadores Carlos Alberto Reyes Maldonado, neste acontecimento que se julgava final.

Como se pode ver no caso da Unemat, os sentidos que as nomeações e designações permitem e evocam vão sendo alterados, fazendo-se enunciar novas nomeações e criando novos sentidos para a universidade.

\section{Considerações Finais:}

Neste artigo nos propusemos analisar a partir de uma abordagem semânticoenunciativa os novos sentidos que se constituíram a partir do último processo renomeativo da Universidade do Estado de Mato Grosso, Unemat, ocorrido em janeiro de 2019, que acabou por envolver a instituição em uma disputa de sentidos que se colocam lado a lado, na forma de renomear Universidade do Estado de Mato Grosso por Universidade Estadual de Mato Grosso Carlos Alberto Reyes Maldonado.

O objetivo apresentado para essa última renomeação era o de prestar uma homenagem ao primeiro reitor da Unemat e um dos seus idealizadores, mas ao renomear como Universidade Estadual, acaba, no nosso modo de entender, por desomenageá-lo.

A substituição do nome Universidade do Estado de Mato Grosso por Universidade Estadual de Mato Grosso separa o sentido do nome da universidade da sua história, que 
sempre trouxe a relação que inclui a forma do Estado de, diferentemente do padrão mais habitual no Brasil. O que esta última renomeação faz é desviar-se da história da própria instituição e adotar o nome mais comum nas demais universidades estaduais do Brasil. Isto muda o fundamento da nomeação inicial.

No nosso entendimento, essa renomeação da Universidade do Estado de Mato Grosso por Universidade Estadual de Mato Grosso Carlos Alberto Reyes Maldonado frusta a homenagem pretendida, visto que, pela substituição de do Estado (que se sustenta desde a fundação) por estadual, nega todo o trabalho fundador de contar a história da instituição como sendo a Universidade do Estado de Mato Grosso. Esse ato, também nega o sentido que professores, alunos e servidores dessa instituição queriam manter ao aprovarem em conselhos a homenagem ao professor Maldonado para integrar o nome da universidade.

A despeito da sua última renomeação, a Unemat, continua defendendo e evocando para si o nome de Universidade do Estado de Mato Grosso. Dada essa circunstância, ainda não se pode ter como fechado esse ciclo de renomeações, uma vez que há articulações por parte da gestão da universidade em assegurar o nome com o qual a universidade foi fundada, e sendo agregado o aposto, como forma de homenagear um dos seus idealizadores. A forma como esse processo se dará ficará para um estudo posterior, caso de fato ocorra, ou continuará existindo esse litígio que conta a história da Unemat.

\section{REFERÊNCIAS}

BENFICA, Tiago Alinor Hoissa. História e universidade : a institucionalização do campo histórico na Universidade Estadual de Mato Grosso/Universidade Federal de Mato Grosso do Sul (1968-1990). (Tese Doutorado em História) Dourados, MS : UFGD, 2016. História do ensino superior em Mato Grosso: das iniciativas frustradas à criação de um sistema universitário. Revista Brasileira de História da Educação, Volume 19, e052, Maringá - PR, 2019. https://doi.org/10.4025/rbhe.v19.2019.e052

GUIMARÃES, E. Os limites do sentido: um estudo histórico e enunciativo da linguagem. Campinas, SP: Pontes Editores, 1995.

. Semântica do acontecimento: um estudo enunciativo da designação. Campinas, SP:

Pontes Editores, 2017. $4^{\text {a }}$ edição

. Semântica Enunciação e Sentido. Campinas, SP: Pontes Editores, 2018. 
Análise de texto - procedimentos, análises, ensino. $2^{\circ}$ ed. São Paulo: Hucitec, 2012. $1^{\mathrm{a}}$ reimpressão 2017.

. A palavra: Forma e Sentido. Pontes. Campinas, 2007.

. Semântica e Pragmática. IN: GUIMARÃES, Eduardo e ZOPPI-FONTANA,

Mônica. Introdução às Ciências da Linguagem - A Palavra e a Frase. Campinas - SP: Pontes Editores, 2010: $2^{\mathrm{a}}$ edição.

ZATTAR, Neuza Benedita da Silva. Do IESC à Unemat: uma história plural 1978-2008.

Cáceres - MT, Editora Unemat, 2008.

et al. Unemat: Uma história que faz parte de muitas outras. Cáceres - MT, Editora Unemat, 2018.

CÁCERES - MT, Decreto no 190 do município de Cáceres de 20 de julho de 1978

ESTATO DE MATO GROSSO, Lei Estadual no 4.960 de 19 de dezembro de 1985

. Lei Estadual no $\mathbf{5 . 4 9 5}$ de 17 de julho de 1989

. Lei Complementar $\mathbf{n}^{\mathbf{0}} \mathbf{1 4}$ de 16 de janeiro de 1992

. Lei Complementar $\mathbf{n}^{\circ} \mathbf{3 0}$ de 15 de dezembro de 1993

. Lei Complementar no 611, de 28 de janeiro de 2019,

- Projeto de lei complementar $\mathbf{n}^{\mathbf{0}} \mathbf{3 / 2 0 1 6}$, protocolo $n^{\circ} 364 / 2016$, processo $n^{\circ}$ 111/2016. Secretaria de serviços legislativos 18/02/2016.

JORNAL DE MATO GROSSO, "Na festa do bicentenário, Cáceres ganha uma faculdade", edição de 23 a 30 de julho de 1978

UNEMAT, portal. "Definitivo - Unemat passa a ser Universidade do Estado de Mato Grosso Carlos Alberto Reyes Maldonado", de 16 de janeiro de 2019, (www.unemat.br )

UFMS, portal. Histórico, (www.ufms.br) 